\title{
La carga de la enfermedad por rotavirus en niños menores de cinco años, Colombia, 2004
}

\author{
Diana Carolina Cáceres, ${ }^{1}$ Dioselina Peláez, ${ }^{1}$ Nubia Sierra, ${ }^{1}$ \\ Eduardo Estrada ${ }^{2}$ y Luis Sánchez ${ }^{3}$
}

Forma de citar Cáceres DC, Peláez D, Sierra N, Estrada E, Sánchez L. La carga de la enfermedad por rotavirus en niños menores de cinco años, Colombia, 2004. Rev Panam Salud Publica. 2006;20(1):9-21.

RESUMEN Objetivos. Establecer un sistema de vigilancia intrahospitalaria de la diarrea en niños menores de 5 años, estimar la carga de la enfermedad por rotavirus e identificar los genotipos más frecuentes de rotavirus.

Métodos. Se incluyó en este estudio a niños hospitalizados por complicaciones graves de la diarrea en tres centros asistenciales de Santa Fe de Bogotá, Barranquilla y Cali, Colombia. Se utilizó un método de enzimoinmunoanálisis en fase sólida (ELISA) para la detección de rotavirus y un método de reacción en cadena de la polimerasa con transcripción inversa (RT$P C R$ ) para la genotipificación. Se determinaron las frecuencias, la tendencia central y la dispersión de las variables. Se realizó un análisis estratificado y un análisis con dos variables, mediante una prueba de la $\chi^{2}$ o una prueba exacta de Fisher, o una prueba de la $\chi^{2}$ para evaluar la tendencia, según los datos. Se establecieron los riesgos relativos. Para el análisis de la tendencia, se utilizaron la regresión lineal, los coeficientes de correlación y los valores de P.

Resultados. Entre diciembre de 2003 y noviembre de 2004 se hospitalizó a 893 niños en los tres centros participantes en el estudio, de los cuales el 68\% tenía entre 6 y 23 meses de edad. Un 2,7\% de los pacientes ingresados presentaba un cuadro de choque hipovolémico y un 1,2\% falleció. Solo un $57 \%$ de las madres habia administrado a sus hijos una solución de rehidratación oral antes de la hospitalización. La infección por rotavirus motivó un 50\% de las hospitalizaciones (coeficiente de correlación $[\mathrm{r}]>0,8)$ y se relacionó con intolerancia a la vía oral (riesgo relativo $[R R]=1,45 ;$ intervalo de confianza del 95\% [IC95\%]: 1,24 - 1,69; $\mathrm{P}<$ $0,0000)$ y vómito incoercible $(R R=1,47 ;$ IC95\%:1,16 - 1,86; $\mathrm{P}<0,01)$. La infección por rotavirus ocasionó una muerte por cada 2000 niños; 16 hospitalizaciones por cada 1000 niños y 631 consultas por cada 1000 niños. Se identificó estacionalidad en los genotipos G1P[8], G2P[4] y G3P[8] de rotavirus, que no varió a pesar de la distancia geográfica y las diferencias de temperatura, humedad y precipitación entre las tres ciudades.

Conclusiones. La infección por rotavirus es una causa importante de morbilidad y mortalidad por diarrea, especialmente en los primeros años de vida, cuando los niños están más expuestos a las complicaciones graves. Es necesario que las estrategias de prevención tengan un alto impacto antes de los 6 meses de edad. La vacunación contra el rotavirus puede ser una buena estrategia complementaria de intervención. No se encontró en la literatura internacional ninguna descripción anterior de la estacionalidad de los genotipos de rotavirus. Es importante hacer estudios de costo-efectividad para favorecer la inversión de recursos según las necesidades de la población y continuar la vigilancia para ampliar el conocimiento del comportamiento de este virus.

Palabras clave Vigilancia epidemiológica, rotavirus, prevención, vacunación, Colombia.

1 Instituto Nacional de Salud, Santa Fe de Bogotá, Colombia.
2 Clínica Infantil Colsubsidio, Santa Fe de Bogotá, Colombia.
3 Hospital Pediátrico de Barranquilla, Colombia. 
En los países en desarrollo, la enfermedad diarreica aguda sigue siendo una causa importante de mortalidad en niños menores de 5 años, a pesar de la disminución del número mundial de casos: 3,3 millones de casos en 1992 frente a 2,1 millones en 2000. Por el contrario, la morbilidad por esta enfermedad ha permanecido notablemente estable, a pesar de los recursos invertidos, los programas de prevención de la deshidratación, la ampliación de la cobertura del acceso al agua, el aumento en la calidad del agua y la mejora en el acceso a los servicios de salud (1-4).

En estos países, los niños presentan entre tres y diez episodios de diarrea en los primeros cinco años de vida, con una incidencia estimada de 3,8 episodios por niño y por año en los menores de 12 meses y de 2,1 episodios por niño y por año en los niños de entre 1 y 4 años. Teniendo en cuenta que la enfermedad diarreica aguda afecta a casi todos los niños en los primeros años de vida, que el número de episodios por niño es considerable y que a pesar del desarrollo y la difusión del tratamiento de rehidratación oral se producen 9 millones de hospitalizaciones de menores de 5 años en el mundo $(1,3,5)$, esta enfermedad sigue siendo un problema prioritario de salud pública.

Entre las causas de diarrea, el rotavirus presenta fuerte asociación con la enfermedad grave, principalmente entre los 6 y los 24 meses de edad (6, 7). Se calcula que en los países en desarrollo, esta infección ocasiona cada año 111 millones de episodios de gastroenteritis, 25 millones de consultas médicas, 2 millones de hospitalizaciones y entre 352000 y 592000 muertes, un $82 \%$ de las cuales se produce en los países más pobres (3).

Si bien las estimaciones del impacto de la infección por rotavirus son sólidas y concordantes, la Organización Mundial de la Salud (OMS) y la Organización Panamericana de la Salud (OPS) consideran que se requiere mayor información para evaluar la relación costo-efectividad de la vacuna y determinar los genotipos y los serotipos de circulación más frecuentes en la región (8-10).
La mayoría de las infecciones por rotavirus se debe a los serotipos P y G del grupo A (6). En la región de América, los serotipos más frecuentes son G1 y G2, seguidos de G3 y G4; con menor frecuencia circulan G9, G5 y G10. Entre los genotipos P, la mayor circulación corresponde a P[4] y P[8], seguidos de P[6] y P[10]. En general, las principales combinaciones son G1P[8], G2P[4] y G3P[8]. Sin embargo, se encuentran variaciones según los meses y los años estudiados (11-18).

$\mathrm{Al}$ igual que en otros países en desarrollo, en Colombia la diarrea sigue siendo una causa importante de muerte. Según el Departamento Administrativo Nacional de Estadística (DANE), entre 1990 y 2001 la mortalidad por diarrea pasó de 45,4 a 21,5 por 100000 niños menores de 5 años; por grupos de edad, se observó un descenso en la mortalidad de menores de 1 año (de 161 a 77 por 100 000), mientras que entre los niños de entre 1 y 4 años, los valores permanecieron estables (alrededor de 7,8 por 100 000) en los últimos seis años (19).

Entre 1979 y 1999, se publicaron ocho estudios sobre la infección por rotavirus en Colombia. En ellos se encontró que los niños de entre 6 y 11 meses eran los más afectados por esta enfermedad, seguidos de los de 12 a 23 meses. La proporción de positividad respecto a la detección de rotavirus osciló entre un $48 \%$ y un $35,5 \%$ en los niños hospitalizados y entre un $14 \%$ y un $55 \%$ en los niños atendidos ambulatoriamente. Cabe mencionar que uno de los estudios en pacientes ambulatorios, en el que se encontró una positividad mayor de un 32\%, se realizó durante una epidemia que afectó a gran parte de la población de la ciudad $(18,20-28)$.

En cuanto a los genotipos, entre 1998 y 1999 se aisló el rotavirus en el 40,4\% de 111 muestras de materia fecal analizadas en un hospital de Cartagena; con mayor frecuencia se identificaron los genotipos P[4], P[6] (correspondientes a los serotipos P1B y P2 respectivamente) y G3 y G9 (29). Con anterioridad, Correa y colaboradores habían identificado el serotipo G3 en cuatro de ocho muestras estudiadas (27).
Por último, entre 2000 y 2001, el Instituto Nacional de Salud (INS) de Colombia realizó un estudio de casos y testigos, con el objetivo de establecer una relación entre la infección por rotavirus y la gravedad de la diarrea en niños menores de 5 años, y determinar los factores socioeconómicos, ambientales y de acceso a los servicios de salud que favorecían la deshidratación (30). En este estudio se encontró que los niños infectados por el rotavirus tenían mayor riesgo de deshidratación (razón de posibilidades $[R P]=3,46$; intervalo de confianza del 95\% [IC95\%]: 1,71 - 7,00).

Con el fin de estimar la carga de la enfermedad por rotavirus (número esperado de acontecimientos relacionados con el virus - muertes, hospitalizaciones y consultas externas - en los primeros cinco años de vida de una cohorte de niños) y establecer los genotipos más frecuentes, entre diciembre de 2003 y noviembre de 2004 se instauró un sistema de vigilancia intrahospitalaria de la diarrea en menores de 5 años en tres instituciones. El estudio se realizó en Santa Fe de Bogotá, Barranquilla y Cali, ciudades ubicadas en tres de las cinco regiones del país, que presentan diferencias en la mortalidad por enfermedad diarreica aguda y en las características sociodemográficas y culturales, y reúnen un porcentaje importante de la población del país.

Bogotá, la ciudad más densamente poblada del país, se encuentra en la región central, a 2547 metros sobre el nivel del mar (m.s.n.m.); la temperatura media mensual oscila entre 13,3 y $14,5^{\circ} \mathrm{C}$; la precipitación anual, entre 579,8 y $930 \mathrm{~mm}$ de agua, y la humedad relativa, entre un $76 \%$ y un $83 \%$. Barranquilla está ubicada en la costa atlántica, a 2 m.s.n.m.; la temperatura media oscila entre 26,9 y $29^{\circ} \mathrm{C}$, la precipitación anual, entre 478 y $808 \mathrm{~mm}$ de agua, y la humedad relativa, entre un $79 \%$ y un $83 \%$. Por último, Cali se encuentra en la región occidental, a 954 m.s.n.m.; la temperatura media oscila entre 24,8 y $26,6^{\circ} \mathrm{C}$, la precipitación anual, entre 529 y $1010,9 \mathrm{~mm}$ de agua, y la humedad relativa, entre un $62 \%$ y un $74 \%$.

En cada una de estas tres ciudades, se seleccionó una institución de salud 
con alto reconocimiento de la comunidad, que funcionaba como centro de referencia para la atención pediátrica: el Hospital Pediátrico de Barranquilla, el Hospital Infantil Club Noel de Cali y la Clínica Infantil Colsubsidio de Bogotá. El Hospital Pediátrico de Barranquilla es una institución pública de atención secundaria que en 2003 atendió a 63019 niños menores de 5 años, 8487 por enfermedad diarreica aguda; de ellos, se hospitalizaron 743 (9\%); la diarrea fue la segunda causa de consulta y de hospitalización de menores de 1 año y de niños de 1 a 4 años. El Hospital Infantil Club Noel de Cali es una institución privada de atención secundaria que en 2003 atendió a 31159 menores de 5 años, de los cuales se hospitalizaron 2370 (7,6\%); la diarrea fue la segunda causa de hospitalización. Por último, la Clínica Infantil Colsubsidio de Bogotá es una institución de atención terciaria, que en 2001 atendió a 3200 niños con diarrea, lo que equivale a un $9 \%$ del número total de niños afiliados a la institución; de ellos, se hospitalizaron 352 (11\%) por un cuadro grave.

\section{MATERIALES Y MÉTODOS}

La diarrea se definió como la presencia de tres o más deposiciones líquidas por día; el vómito incoercible, como la presencia de seis o más episodios de vómito en una hora, a pesar de la administración adecuada de solución de rehidratación oral; y la intolerancia a la vía oral, como la presencia de vómito persistente, de intensidad suficiente para interferir en la alimentación o la hidratación del niño. Se incluyó en el estudio a todos los niños que cumplieron con la definición de "caso sospechoso" y estuvieron hospitalizados durante 8 horas o más. Se consideró "caso sospechoso" todo incidente de diarrea en un niño menor de 5 años que presentara deshidratación, intolerancia a la vía oral, vómito incoercible $\mathrm{u}$ otra complicación grave de la diarrea. Se definió como "caso confirmado de infección por rotavirus" todo caso sospechoso con resultado positivo en el inmunoanálisis en fase sólida (ELISA) de detección de rotavirus.

Se excluyó del estudio a los niños que presentaban cualquiera de los siguientes: presencia de una enfermedad infecciosa concomitante que pudiera ser la causa de la gravedad del cuadro clínico y de la hospitalización; diarrea aparecida tres o más días después de la hospitalización por cualquier otro problema de salud; diarrea de más de 14 días de evolución en el momento del ingreso; diagnóstico de intoxicación alimentaria; diagnóstico de enfermedad diarreica crónica o recurrente; antecedentes de alergia alimentaria; enfermedad sistémica que favoreciera o cuya manifestación cardinal fuera la enfermedad diarreica; íleo paralítico de más de 24 horas de evolución y procedencia, en los 30 días anteriores al ingreso, de áreas fuera del casco urbano de las ciudades del estudio.

Se utilizó en el estudio un cuestionario previamente validado (31). Se tuvieron en cuenta las recomendaciones técnicas del protocolo genérico de la OMS (8). Se diseñaron bases de datos adicionales, con el fin de recoger información pasiva del número total de consultas, de las primeras causas de morbilidad y del diagnóstico de intususcepción en niños menores de 5 años, discriminando por grupos de edad y meses del año. Las bases de datos se remitieron semanalmente por vía electrónica al INS. El médico coordinador del estudio realizó periódicamente el control de la calidad de la información. Los informes trimestrales se enviaron a las instituciones participantes en el estudio y se analizaron conjuntamente $y$, siempre que fue posible, con los responsables de la salud pública o de la toma de decisiones en las tres ciudades participantes.

Las variables se clasificaron en diferentes grupos para el análisis: datos sociodemográficos, datos clínicos, de seguimiento y de evolución de la enfermedad, tratamiento anterior a la hospitalización, resultados en el ELISA de detección de rotavirus, resultados de los exámenes de laboratorio solicitados en el hospital, cantidad y costo de cada una de las intervenciones, in- sumos o medicamentos utilizados durante la hospitalización. Para el análisis de las variables ambientales se utilizó la información del Instituto de Hidrología, Meteorología y Estudios Ambientales (IDEAM) de Colombia.

Además de las bases de datos desarrolladas para el estudio, para estimar la carga de la enfermedad por rotavirus se utilizaron las informaciones de las bases de datos SIS-110 y SIS-112 del Ministerio de Salud de 1991 a 1996, y la información de la Base de Datos Única del Registro Individual de Prestación de Servicios de Salud (RIPS) remitida al Ministerio de la Protección Social entre 2001 y 2003.

Los datos se procesaron con los programas informáticos Epi-Info 6.04 (32) y Stata (33). Se realizó un análisis con una variable en el que se determinaron las frecuencias, la tendencia central y la dispersión de las variables continuas. Se realizó asimismo un análisis con dos variables, mediante la prueba de la $\chi^{2}$ o la prueba exacta de Fisher — según la presentación de los datosy el cálculo de los valores de $P$ correspondientes. Cuando estuvo indicado, se realizó una prueba de la $\chi^{2}$ para evaluar la tendencia y una estratificación para controlar confusores. Se determinaron los riesgos relativos, sus intervalos de confianza del 95\% [IC95\%] y los valores de P. Se efectuó un análisis estratificado por ciudades. Se utilizó una regresión lineal para el análisis de tendencia en series de tiempo con menos de 48 observaciones, buscando el modelo matemático de mayor ajuste; se determinó el coeficiente de determinación $\left(r^{2}\right)$, los coeficientes de correlación $(r)$ y los valores de $P(34,35,36)$.

En junio de 2004, se produjo un brote de diarrea por norovirus en Barranquilla que incrementó de manera abrupta e importante la hospitalización de menores de 5 años, con respecto al período comprendido entre diciembre de 2003 y mayo de 2004, cuando este virus prácticamente estuvo ausente. Por esta razón, se reemplazó en el análisis el valor extremo observado en este mes por el valor de predicción estimado por el modelo matemático $(36,37)$. 
En Cali, se desarrolló un protocolo de articulación de los sistemas de vigilancia de la parálisis flácida y la infección por rotavirus, que se probó durante 3 meses en el segundo semestre de 2004. Este protocolo se realizó con participación de los encargados de la vigilancia de la diarrea, la vigilancia epidemiológica, la vigilancia de la parálisis flácida, la promoción del programa de Atención Integrada de las Enfermedades Prevalentes de la Infancia (AIEPI) y los encargados del laboratorio de salud pública del municipio.

El estudio cumplió con los requisitos éticos establecidos en la resolución N. ${ }^{\circ} 008430$ de 1993 del Ministerio de Salud de Colombia y recibió la aprobación del comité de investigaciones del INS y de los comités de ética e investigaciones de la Clínica Infantil Colsubsidio, del Hospital Pediátrico de Barranquilla y del Hospital Infantil Club Noel.

\section{Métodos de laboratorio}

Siempre que fue posible, se tomó una muestra de materia fecal en las primeras 48 horas posteriores a la hospitalización del niño, de volumen superior a $5 \mathrm{~mL}$. Las muestras se mantuvieron durante 8 horas a una temperatura comprendida entre 4 y $8{ }^{\circ} \mathrm{C}$ con paquetes fríos y luego se trasladaron a un laboratorio local con capacidad de almacenamiento a $-70^{\circ} \mathrm{C}$.

Las muestras se remitieron mensualmente al INS. La presencia de rotavirus del grupo A se determinó mediante una prueba de ELISA, utilizando un estuche comercial avalado por la OPS (Pathfinder ${ }^{\circledR}$, Sanofi Diagnostic Pasteur, Francia). El control de la calidad de los resultados de laboratorio se realizó con arreglo a los estándares internacionales (8) y las recomendaciones de la casa productora del reactivo.

De las muestras positivas para rotavirus se extrajo el ARN viral con TRIsol ${ }^{\circledR}$ LS (Invitrogen Corporation). Las bandas de ARN se separaron por electroforesis en gel de poliacrilamida al 7,5\% en tampón de tris-boratoEDTA (TBE), con migración a $100 \mathrm{~V}$ durante 2 h $30 \mathrm{~min}$. Los geles se tiñeron con bromuro de etidio $[1 \mathrm{mg} / \mathrm{mL}]$.

Teniendo en cuenta la representatividad de las muestras, los costos de los reactivos y la eficiencia del laboratorio, se decidió genotipificar el $30 \%$ de las muestras positivas en la prueba de detección de rotavirus. Los genotipos $\mathrm{G}$ y $P$ se evidenciaron por reacción en cadena de la polimerasa con transcripción inversa (RT-PCR) semianidada. Las bandas de ADN viral se separaron por electroforesis en gel de agarosa al 1,5\% en tampón de tris-acetato-EDTA (TAE), con migración a $100 \mathrm{~V}$ durante $95 \mathrm{~min}$. Los geles se tiñeron con bromuro de etidio $[0,05 \mathrm{mg} / \mathrm{mL}]$. Este procedimiento se realizó según las recomendaciones técnicas de los Centros para el Control y la Prevención de Enfermedades (CDC), Atlanta, Georgia, Estados Unidos.

Para la genotipificación G, se utilizaron en la primera amplificación (20 ciclos) los cebadores 9con1 y 9con2, para generar fragmentos del gen VP7 de 905 pares de bases. El cebador 9 con1 se utilizó luego en la segunda amplificación (30 ciclos), con los cebadores específicos de tipo 9T-1 (G1), 9T-2 (G2), 9T-3P (G3), 9T-4 (G4) y 9T9B (G9). Para la genotipificación P, se utilizaron en la primera amplificación los cebadores con 2 y con3, para gene- rar fragmentos del gen 4 de 877 pares de bases. El cebador con3 se utilizó luego en la segunda amplificación (30 ciclos), con los cebadores específicos de tipo 1T-1 (P8), 2T-1 (P4), 3T-1 (P6), 4T-1 (P9), 5T-1 (P10) y ND2 (P11). El porcentaje de virus no identificados fue bajo $(7,5 \%)$. Las muestras que no pudieron tipificarse por este procedimiento se registraron como no tipificables.

Para evaluar la importancia de la infección por rotavirus con respecto a otros virus entéricos, se seleccionaron aleatoriamente 115 muestras de materia fecal tomadas en Barranquilla en los distintos meses del año (37,5\% del total de muestras), las cuales se analizaron simultáneamente para detectar norovirus, adenovirus y astrovirus por pruebas de ELISA específicas para detectar cada virus (Ridascreen ${ }^{\circledR}$, RBiopharm AG, Alemania).

\section{RESULTADOS}

El número de niños incluidos en el estudio en cada una de las ciudades coincidió con el esperado; la pérdida de información en cualquiera de las variables del cuestionario fue inferior a un $10 \%$, sin diferencias entre las ciudades o los grupos de edad. La calidad

FIGURA 1. Distribución por grupos de edad de los niños menores de 5 años hospitalizados por diarrea e ingresados en el sistema de vigilancia intrahospitalaria del rotavirus en la Clínica Infantil Colsubsidio de Santa Fe de Bogotá, el Hospital Infantil Club Noel de Cali y el Hospital Pediátrico de Barranquilla (Colombia), entre diciembre de 2003 y noviembre de 2004

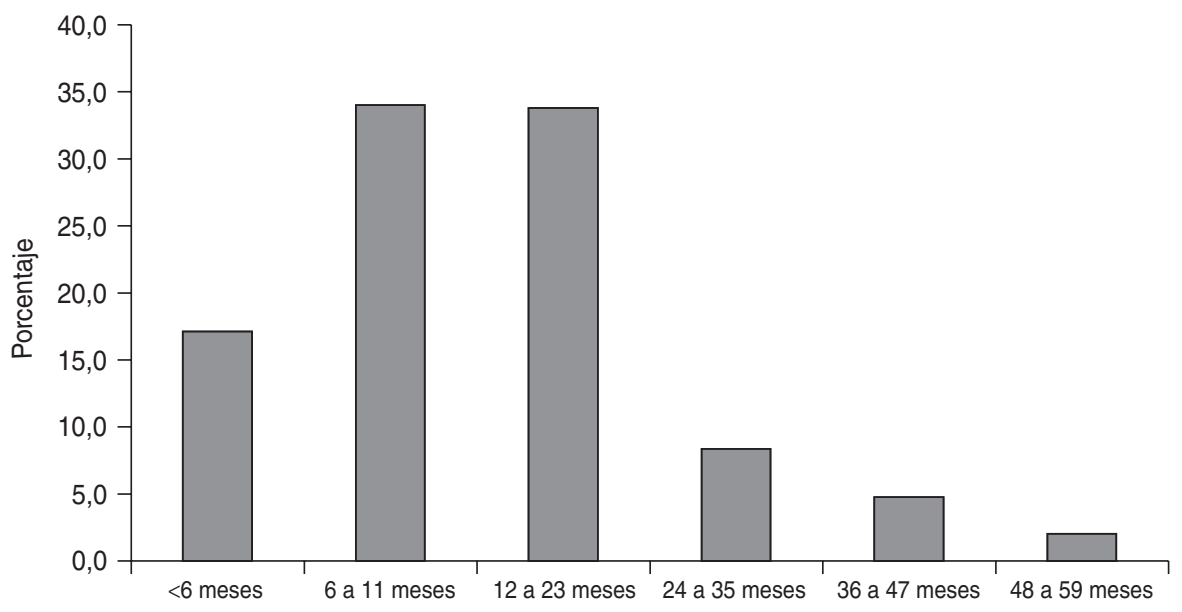


CUADRO 1. Distribución general y por ciudades de las principales variables sociodemográficas y de evolución de la diarrea, de la afiliación a la seguridad social de salud y de las principales complicaciones en los niños menores de 5 años hospitalizados por enfermedad diarreica aguda en la Clínica Infantil Colsubsidio de Santa Fe de Bogotá, el Hospital Infantil Club Noel de Cali y el Hospital Pediátrico de Barranquilla (Colombia), entre diciembre de 2003 y noviembre de 2004

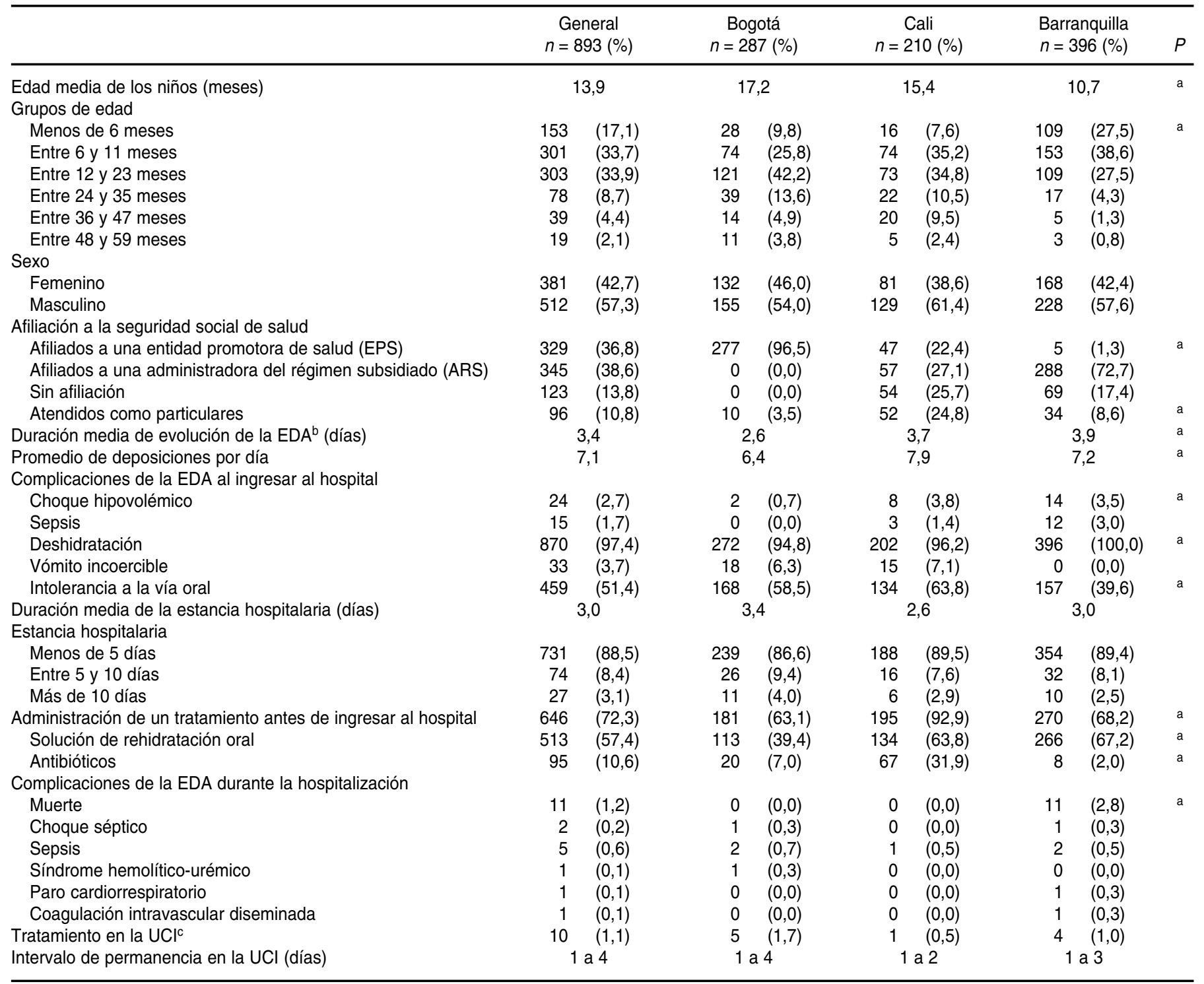

a $P<0,05$.

${ }^{b}$ EDA: enfermedad diarreica aguda.

c UCl: Unidad de Cuidados Intensivos.

de las muestras de materia fecal fue adecuada: las condiciones de almacenamiento y el transporte cumplieron los requisitos establecidos en el protocolo y las recomendaciones internacionales. Se tomaron muestras de materia fecal en más del $80 \%$ de los menores de 5 años ingresados en el sistema de vigilancia.

\section{Demografía y manifestaciones clínicas en los niños}

Entre el $1 .^{\circ}$ de diciembre de 2003 y el 30 de noviembre de 2004, se hospitalizaron en las tres instituciones participantes en el estudio 893 niños que cumplieron con la definición de "caso", de los cuales un $57,3 \%$ (512/ 893) era de sexo mascu- lino. La edad promedio fue de 14 meses (edad mínima: 9 días; edad máxima: 52 meses). La distribución por grupos de edad se presenta en la figura 1 .

$\mathrm{Al}$ ingresar al hospital, casi todos los niños presentaban deshidratación y un 2,7\% (24/893), signos de choque hipovolémico. En el cuadro 1 se presentan otras complicaciones observadas al ingreso. 
Un 72\% (646/893) de los niños había recibido tratamiento farmacológico antes de ingresar al hospital: un 40,4\%, antipiréticos, y un $10,6 \%$, antibióticos (la utilización de este último grupo de medicamentos fue mayor en Cali). Llama la atención que solo un $57 \%$ de los niños había recibido una solución de rehidratación oral antes de la hospitalización (cuadro 1).

La duración media de la estancia hospitalaria fue de 3 días (desviación estándar [DE]: 3,6 días); sin embargo, cabe señalar que un $11 \%$ de los niños permaneció hospitalizado durante cinco días o más. Las principales complicaciones observadas durante la hospitalización se presentan en el cuadro 1. Por su estado de salud crítico requirió tratamiento en la Unidad de Cuidados Intensivos (UCI) un 1\% de los niños (10/893), de los cuales un 50\% permaneció durante un día. No se hallaron diferencias por ciudad en este aspecto (cuadro 1).

Durante el periodo de estudio fallecieron 11 niños menores de 14 meses de edad en Barranquilla, un 37\% (4/11) de ellos en las primeras 24 horas después de ingresar al hospital. Algunas de las características principales de estos niños se presentan en el cuadro 2. Es importante notar que un $80 \%$ de los niños que fallecieron tenía un diagnóstico asociado de desnutrición.

\section{Hospitalización por enfermedad diarreica aguda}

Se observó un comportamiento bimodal en la hospitalización por diarrea de los niños menores de 5 años, con un primer pico en febrero de 2004, un descenso entre marzo y junio, y un nuevo incremento de menor intensidad en agosto.

$\mathrm{Al}$ realizar el análisis por ciudad, se observó en Barranquilla un incremento progresivo en el número de niños hospitalizados por diarrea a partir de diciembre de 2003, el cual alcanzó el valor máximo en junio de 2004, para descender a partir de esta fecha (figura 2).

En Bogotá, la hospitalización por diarrea presentó un comportamiento bimodal similar al general, con un

CUADRO 2. Riesgos relativos de la infección por rotavirus, intervalos de confianza y valores de $\boldsymbol{P}$ correspondientes, según los datos de los sistemas de vigilancia intrahospitalaria del rotavirus de la Clínica Infantil Colsubsidio de Santa Fe de Bogotá, el Hospital Infantil Club Noel de Cali y el Hospital Pediátrico de Barranquilla (Colombia), entre diciembre de 2003 y noviembre de 2004

\begin{tabular}{llll}
\hline \multicolumn{1}{c}{ Variables } & $\mathrm{RR}^{\mathrm{a}}$ & $\mathrm{IC95 \%}^{\mathrm{b}}$ & $P$ \\
\hline Niños de 6 a 23 meses & 1,44 & $1,11-1,86$ & $<0,05$ \\
Intolerancia a la vía oral & 1,45 & $1,24-1,69$ & $<0,000$ \\
Vómito incoercible & 1,47 & $1,16-1,86$ & $<0,01$ \\
Estancia hospitalaria $>5$ días & 0,54 & $0,34-0,87$ & $<0,006$ \\
\hline
\end{tabular}

RR: riesgo relativo

b IC95\%: intervalo de confianza del 95\%.

FIGURA 2. Número de niños menores de 5 años hospitalizados por diarrea según los meses del año en la Clínica Infantil Colsubsidio de Santa Fe de Bogotá, el Hospital Infantil Club Noel de Cali y el Hospital Pediátrico de Barranquilla ${ }^{a}$ (Colombia), entre diciembre de 2003 y noviembre de 2004

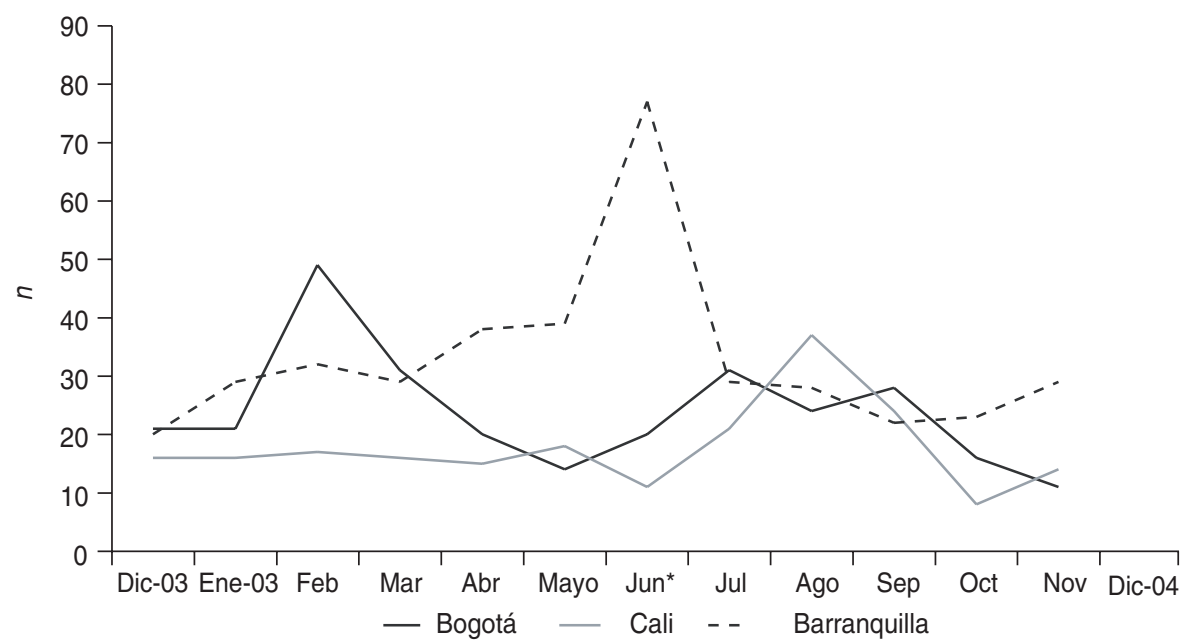

${ }^{a}$ El valor extremo observado en junio en Barranquilla $(n=77)$ se reemplazó por el valor estimado por el modelo matemático $(n=42)$.

máximo en el primer semestre del año - en el mes de febrero- y un segundo pico de menor intensidad entre junio y agosto de 2004, seguido de una disminución del número de niños hospitalizados (figura 2).

Por último, en Cali, el número de niños hospitalizados permaneció casi constante entre diciembre de 2003 y junio de 2004, y presentó un incremento importante en agosto, mes en el que se observó el máximo valor entre todos los meses analizados (figura 2).
La distribución del número de niños hospitalizados por diarrea por grupos de edad y por ciudades se presenta en la figura 3. En las tres ciudades, el mayor porcentaje de hospitalización se encontró entre los 6 y los 23 meses de edad. Llama la atención que el porcentaje de menores de 6 meses hospitalizados en Barranquilla es significativamente mayor que en Cali y Bogotá $(27,5 \%$ [109/396], 7,6\% [16/210] y 9,8\% [28/287] respectivamente; $P<$ $0,00000)$. 
FIGURA 3. Distribución por grupos de edad de los niños menores de 5 años hospitalizados por enfermedad diarreica aguda en la Clínica Infantil Colsubsidio de Santa Fe de Bogotá, el Hospital Infantil Club Noel de Cali y el Hospital Pediátrico de Barranquilla (Colombia), entre diciembre de 2003 y noviembre de 2004

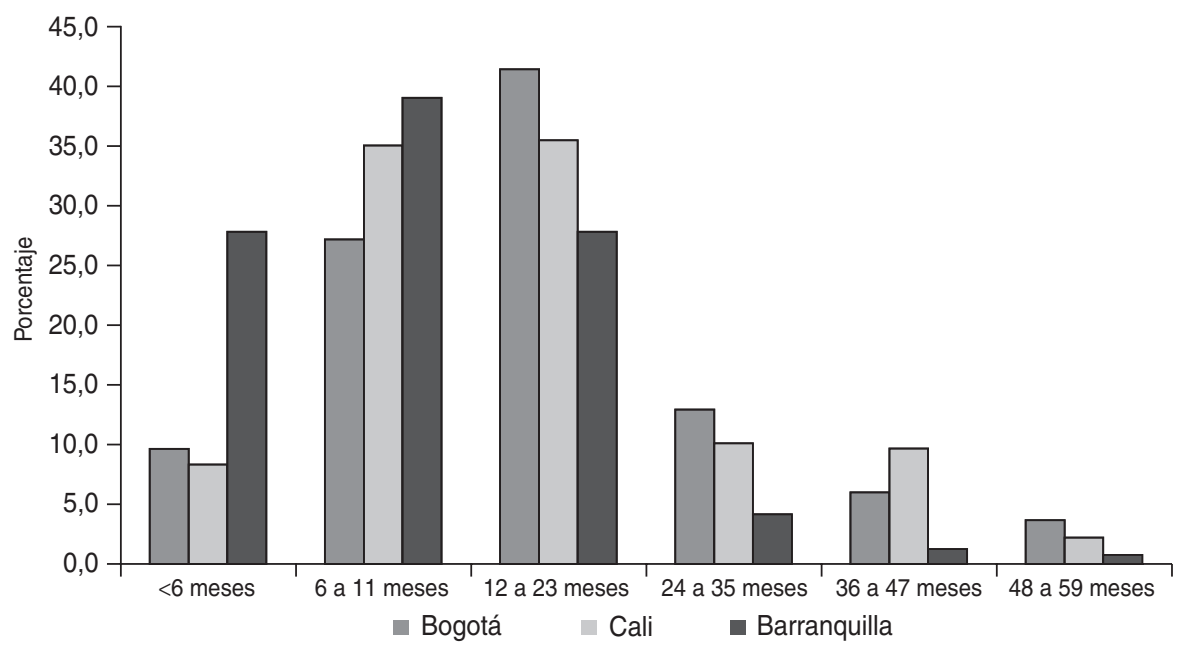

\section{Infección por rotavirus}

Se tomó muestra de materia fecal en el 81,5\% (726/890) de los niños hospitalizados, en las primeras 48 horas siguientes al ingreso en el $96 \%$ de los casos. De las muestras que resultaron positivas respecto del rotavirus, un $96 \%$ se tomó durante dicho periodo.

La proporción de resultados positivos en el ELISA de detección de rotavirus fue de un 49\% (357/726); tres resultados fueron dudosos después de repetir el procedimiento dos veces. Es interesante notar que el aumento o la disminución en el número de resultados positivos se acompañó de una variación simultánea en el número de niños hospitalizados; el coeficiente de correlación entre estas dos curvas fue de 0,79.

El riesgo de infección por rotavirus fue mayor en los niños de 6 a 23 meses de edad. En los niños en quienes se detectó el virus se observó mayor riesgo de intolerancia a la vía oral y vómito incoercible, mientras que la probabilidad de que la duración de la estancia hospitalaria fuese superior a 5 días fue menor (cuadro 2). No se encontraron diferencias en la proporción de resultados positivos en el ELISA de detección de rotavirus según el sexo o la afilia- ción al Sistema General de Seguridad Social en Salud (SGSSS) $(P>0,05)$.

La proporción de muestras positivas respecto del rotavirus en los centros de Bogotá y Cali fue de un 51,8\% (129/ $249)$ y un $57,4 \%(89 / 155)$, respectivamente. Al igual que en la descripción general, se encontró una correlación estrecha entre el número de hospitali- zaciones por diarrea y el número de resultados positivos en el ELISA de detección de rotavirus. En Barranquilla, la proporción de muestras positivas fue de un $43,6 \%$ (139/319), con disociación de las dos curvas entre mayo y junio de 2004, cuando se produjo el brote de norovirus. Sin embargo, debe notarse que se observó una correlación entre el número de hospitalizaciones por diarrea y el número de resultados positivos en el ELISA de detección de rotavirus antes y después de estos meses (figuras 4 a 6). La diferencia en el porcentaje de resultados positivos respecto del rotavirus entre las tres ciudades fue estadísticamente significativa $(P<0,01)$.

Los coeficientes de correlación entre el número de niños hospitalizados y el número de resultados positivos respecto del rotavirus fueron $0,82,0,92 \mathrm{y}$ 0,24 en Bogotá, Cali y Barranquilla, respectivamente. Al corregir el valor extremo observado entre mayo y junio en Barranquilla, según se describió en el apartado de Métodos, el coeficiente de correlación aumentó hasta 0,82 y el porcentaje de resultados positivos respecto del rotavirus, hasta $51,9 \%$.

En las tres ciudades del estudio, el mayor porcentaje de resultados positivos se encontró entre los 6 y los 23 meses de edad, sin diferencia estadís-

FIGURA 4. Número de niños menores de 5 años hospitalizados por diarrea y de resultados positivos en el ELISA de detección de rotavirus según los meses del año en la Clínica Infantil Colsubsidio de Santa Fe de Bogotá (Colombia), entre diciembre de 2003 y noviembre de 2004

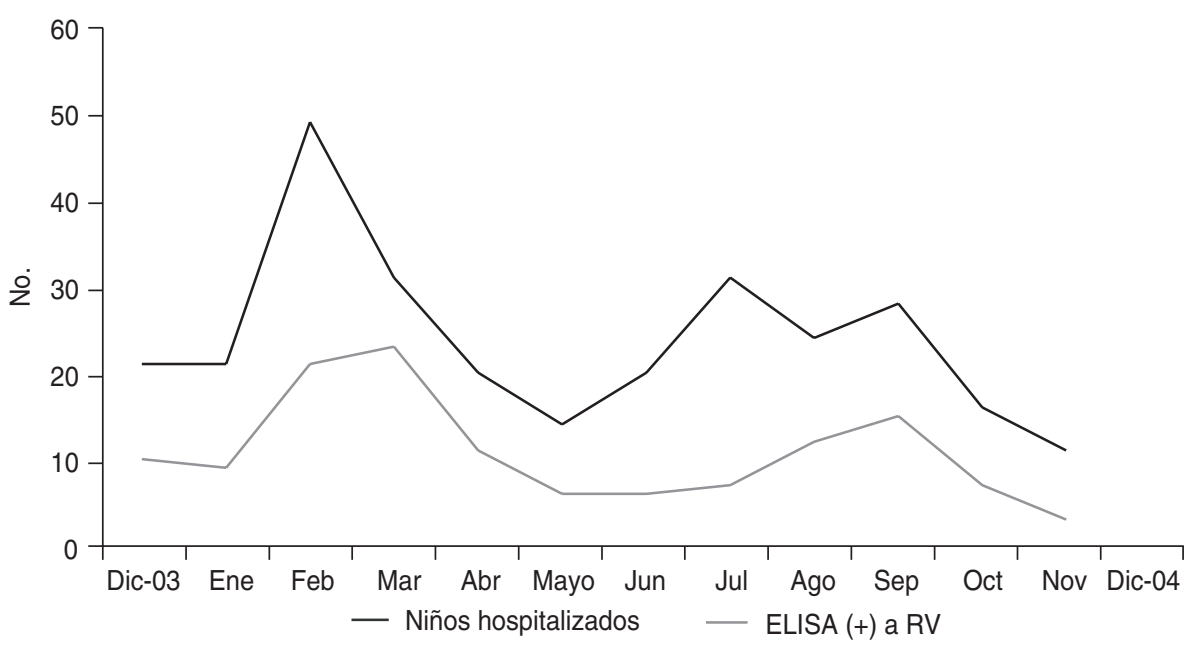


FIGURA 5. Número de niños menores de 5 años hospitalizados por diarrea y de resultados positivos en el ELISA de detección de rotavirus, según los meses del año, en el Hospital Infantil Club Noel de Cali (Colombia), entre diciembre de 2003 y noviembre de 2004

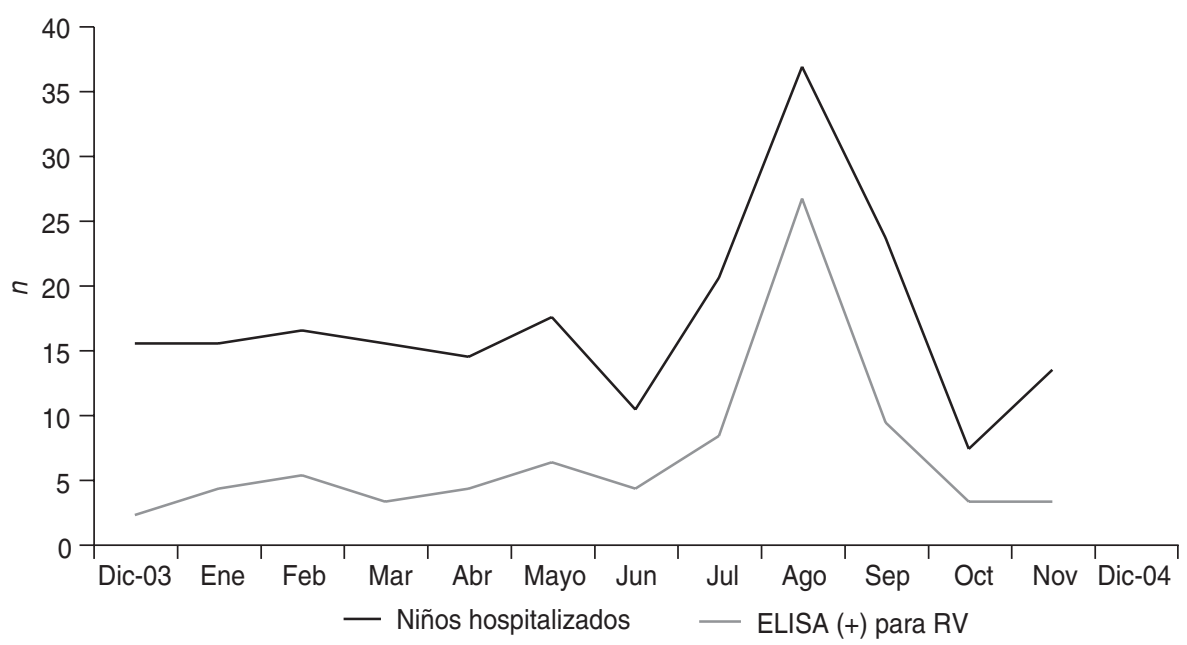

FIGURA 6. Número de niños menores de 5 años hospitalizados por diarrea y de resultados positivos en el ELISA de detección de rotavirus, según los meses del año, en el Hospital Pediátrico de Barranquilla (Colombia), entre diciembre de 2003 y noviembre de 2004 (el valor extremo observado en junio se reemplazó por el valor estimado por el modelo matemático)

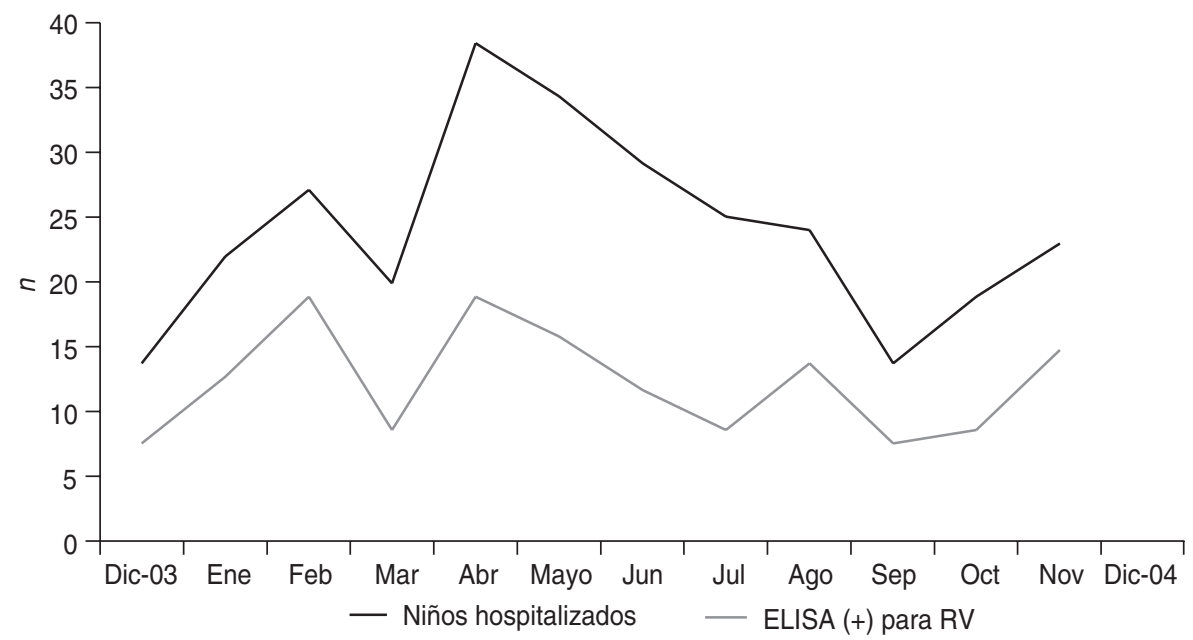

tica entre ellas (Bogotá: 74,4\%, Cali: $75,3 \%$, Barranquilla: 77,7\%; $P>0,05)$. Al igual que en la descripción general, se encontró mayor riesgo de infección por rotavirus en los niños de 6 a 23 meses de edad; el riesgo relativo osciló entre 1,33 en Bogotá y 1,53 en Cali; sin embargo, el IC95\% incluyó el valor nulo en estas dos últimas ciudades. No se encontró diferencia en el nú- los casos respecto del rotavirus, con una frecuencia sensiblemente menor de los otros virus.

Solo se pudo tomar una muestra de materia fecal al 54,5\% (6/11) de los niños que fallecieron en Barranquilla. De las muestras de los niños que fallecieron tres o más días después de la hospitalización, una (20\%) fue positiva respecto del rotavirus; esta muestra se obtuvo en las primeras 24 horas después del ingreso. Llama la atención que los cinco niños en quienes no se pudo tomar una muestra fallecieron en los dos primeros días después de ingresar al hospital y tres de ellos (60\%), el primer día (cuadro 3).

Con la información proveniente del sistema de vigilancia y de las bases de datos disponibles, se estimó que en 2004 la infección por rotavirus ocasionó en Colombia una muerte por cada 2000 niños, 16 hospitalizaciones por cada 1000 niños y 631 consultas por cada 1000 niños.

\section{Genotipificación del rotavirus}

Se analizaron 199 muestras de materia fecal con resultado positivo en el ELISA de detección de rotavirus: 65 en Bogotá; 74 en Barranquilla y 60 en Cali. De ellas, un 7,5\% (15/199) proporcionó un resultado negativo.

En general, los genotipos más frecuentemente identificados fueron G3[P8] (32,7\%; 65/199), G2P[4] (21,1\%; 42/199) y G1P[8] (19,1\%; 38/199). La circulación de otros genotipos fue muy discreta. Se detectaron genotipos mixtos en 8,5\% de las muestras (cuadro 4).

En Bogotá, el genotipo más frecuente fue G1P[8] (36,9\%), seguido de G3P[8] $(29,2 \%)$ y G2P[4] $(16,9 \%)$. En Barranquilla, la circulación de G3P[8] fue casi dos veces superior a la de G2P[4], mientras que el genotipo G1P[8] fue sensiblemente más discreto. Por último, en Cali, la circulación de los genotipos G2[P4] y G3P[8] fue similar. Algunas de estas diferencias fueron estadísticamente significativas $(P<0,05)$.

$\mathrm{Al}$ discriminar según los meses del año, se encontró que el genotipo G2P[4] presentó una tendencia descen- 
FIGURA 7. Distribución de las muestras positivas respecto del rotavirus, el norovirus, el adenovirus y el astrovirus, según los datos del sistema de vigilancia intrahospitalaria del rotavirus del Hospital Pediátrico de Barranquilla, entre diciembre de 2003 y diciembre de 2004

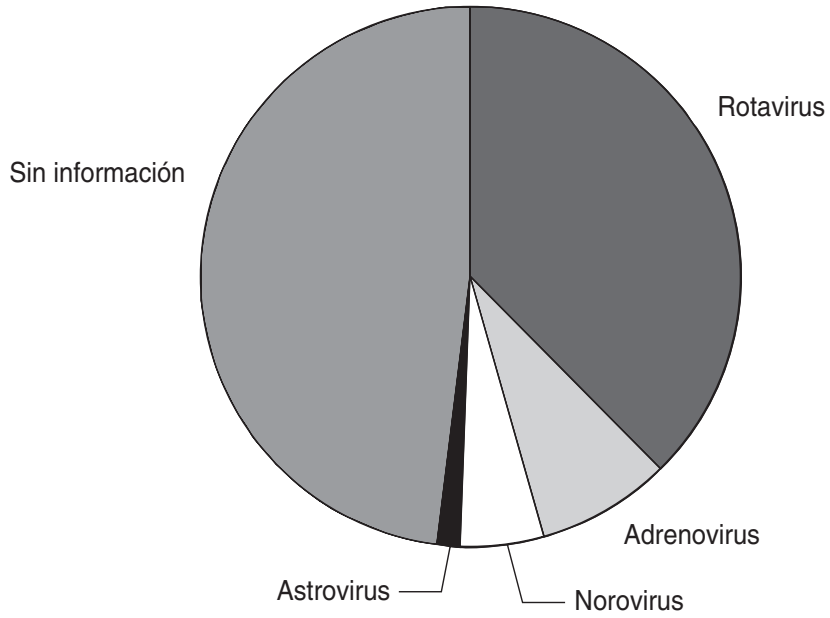

CUADRO 3. Algunas variables de interés relativas a los niños ingresados en el sistema de vigilancia intrahospitalaria del rotavirus que fallecieron por diarrea en el Hospital Pediátrico de Barranquilla, Colombia, entre diciembre de 2003 y noviembre de 2004

\begin{tabular}{|c|c|c|c|c|c|c|}
\hline Niño & $\begin{array}{c}\text { Edad } \\
\text { (meses) }\end{array}$ & $\begin{array}{c}\text { ELISA }^{a} \text { de } \\
\text { detección } \\
\text { de RV }\end{array}$ & $\begin{array}{c}\text { Duración de } \\
\text { la hospitalización } \\
\text { antes de } \\
\text { la muerte (días) }\end{array}$ & $\mathrm{DNT}^{\mathrm{c}}$ & Septicemia & $\begin{array}{c}\text { Choque } \\
\text { hipovolémico }\end{array}$ \\
\hline 1 & 5 & Negativo & 35 & Sí & Sí & No \\
\hline 2 & 3 & Negativo & 15 & Sí & Sí & No \\
\hline 3 & 4 & Negativo & 7 & Sí & Sí & No \\
\hline 4 & 2 & Positivo & 4 & Sí & No & No \\
\hline 5 & 10 & Negativo & 3 & Sí & Sí & No \\
\hline 6 & 7 & $\ldots{ }^{d}$ & 2 & Sí & No & No \\
\hline 7 & 6 & $\ldots d^{d}$ & 2 & Sí & Sí & No \\
\hline 8 & 6 & Negativo & 1 & No & No & Sí \\
\hline 9 & 13 & $\ldots d^{d}$ & 0 & Sí & Sí & No \\
\hline 10 & 1 & $\ldots{ }^{d}$ & 0 & No & No & Sí \\
\hline 11 & 9 & $\ldots{ }^{d}$ & 0 & Sí & Sí & Sí \\
\hline
\end{tabular}

a ELISA: enzimoinmunoanálisis en fase sólida

${ }^{\mathrm{b}} \mathrm{RV}$ : rotavirus.

${ }^{c}$ DNT: desnutrición.

${ }^{\mathrm{d}}$ No se pudo tomar ninguna muestra de materia fecal por el estado crítico de salud del niño.

dente, con mayor frecuencia de circulación entre enero y junio de 2004, mientras que el genotipo G3P[8] presentó un comportamiento contrario, con una tendencia ascendente y mayor frecuencia de circulación en el segundo semestre. Por último, en mitad de año, cuando la circulación de los dos geno- tipos anteriores era discreta, se observó la mayor circulación de G1P[8] (figura 8). Estas variaciones estacionales fueron similares y simultáneas en las tres ciudades estudiadas, a pesar de la distancia geográfica entre ellas y las diferencias de altura sobre el nivel del mar, temperatura y humedad relativa.

\section{DISCUSIÓN}

A pesar de los avances logrados en Colombia en los últimos años, la diarrea en menores de 5 años sigue siendo un problema importante de salud pública. En la morbilidad por diarrea influyen la pobreza, la edad de los niños, la falta de afiliación a la seguridad social de salud, la desnutrición, la lactancia materna inadecuada, la deficiencia en el acceso y la calidad de la atención de los servicios de salud, entre otros factores de riesgo que se pueden mejorar con programas eficaces como el de Atención Integrada de las Enfermedades Prevalentes de la Infancia (AIEPI) y el programa contra la enfermedad diarreica aguda (30, 38-49).

Sin embargo, es probable que el impacto de estos programas de promoción y prevención no sea el esperado, teniendo en cuenta que se encontró una correlación entre la gravedad de la enfermedad diarreica aguda y la infección por rotavirus, que un $50 \%$ de las hospitalizaciones se debió a este agente, que el riesgo de intolerancia a la vía oral y de vómito incoercible fue mayor en los niños infectados por el virus - lo que dificultó la hidratación oral-y que a pesar de los esfuerzos y los recursos invertidos por el Gobierno en las últimas décadas para fomentar el uso de la solución de rehidratación oral, solo un poco más de la mitad de las madres la utilizaron para prevenir la deshidratación. En estas circunstancias, la vacunación contra el rotavirus puede ser una de las intervenciones más eficaces para disminuir la sobrecarga de los servicios de salud y la morbilidad por diarrea.

En nuestro estudio, así como en otros estudios nacionales e internacionales, el mayor porcentaje de hospitalización por diarrea y de infección por rotavirus se encontró entre los 6 y los 23 meses de edad (6-11, 21-23, 30, 50$51)$, cuando los niños son más vulnerables a la enfermedad grave, la aparición de complicaciones y la muerte por deshidratación. Asimismo, todos los niños que fallecieron en el estudio eran menores de 14 meses y la tasa de mortalidad notificada al DANE fue mayor en los menores de 1 año de edad. Por 
CUADRO 4. Genotipos de rotavirus identificados en el estudio de la carga de la enfermedad por rotavirus en la Clínica Infantil Colsubsidio de Santa Fe de Bogotá, el Hospital Infantil Club Noel de Cali y el Hospital Pediátrico de Barranquilla (Colombia), entre diciembre de 2003 y diciembre de 2004

\begin{tabular}{|c|c|c|c|c|c|c|c|c|}
\hline Genotipo & \multicolumn{2}{|c|}{$\begin{array}{l}\text { General } \\
n \quad(\%)\end{array}$} & & $\begin{array}{c}\text { gotá } \\
(\%)\end{array}$ & \multicolumn{2}{|c|}{ Barranquilla } & & $\begin{array}{l}\text { Cali } \\
(\%)\end{array}$ \\
\hline G3P[8] & 65 & $(32,7)$ & 19 & $(29,2)$ & 30 & $(40,5)$ & 16 & $(26,7)$ \\
\hline G2P $[4]$ & 42 & $(21,1)$ & 11 & $(16,9)$ & 16 & $(21,6)$ & 15 & $(25,0)$ \\
\hline G1P[8] & 38 & $(19,1)$ & 24 & $(36,9)$ & 3 & $(4,1)$ & 11 & $(18,3)$ \\
\hline G9P[8] & 4 & $(2,0)$ & 1 & $(1,5)$ & 0 & $(0,0)$ & 3 & $(5,0)$ \\
\hline G2P[10] & 3 & $(1,5)$ & 1 & $(1,5)$ & 1 & $(1,4)$ & 1 & $(1,7)$ \\
\hline G1P[4] & 2 & $(1,0)$ & 0 & $(0,0)$ & 2 & $(2,7)$ & 0 & $(0,0)$ \\
\hline G9P[6] & 2 & $(1,0)$ & 2 & $(3,1)$ & 0 & $(0,0)$ & 0 & $(0,0)$ \\
\hline G2P[8] & 2 & $(1,0)$ & 0 & $(0,0)$ & 0 & $(0,0)$ & 2 & $(3,3)$ \\
\hline G4P[4] & 1 & $(0,5)$ & 0 & $(0,0)$ & 1 & $(1,4)$ & 0 & $(0,0)$ \\
\hline Mixtos & 17 & $(8,5)$ & 4 & $(6,2)$ & 7 & $(9,5)$ & 6 & $(10,0)$ \\
\hline No tipificables $\mathrm{G}$ & 1 & $(0,5)$ & 0 & $(0,0)$ & 1 & $(1,4)$ & 0 & $(0,0)$ \\
\hline No tipificables $P$ & 7 & $(3,5)$ & 1 & $(1,5)$ & 4 & $(5,4)$ & 2 & $(3,3)$ \\
\hline Negativos & 15 & $(7,5)$ & 2 & $(3,1)$ & 9 & $(12,2)$ & 4 & $(6,7)$ \\
\hline Total & \multicolumn{2}{|c|}{199} & \multicolumn{2}{|c|}{65} & \multicolumn{2}{|c|}{74} & \multicolumn{2}{|c|}{60} \\
\hline
\end{tabular}

FIGURA 8. Circulación de los tres principales genotipos de rotavirus -G1P[8], G2P[4] y G3P[8]- según los meses del año en la Clínica Infantil Colsubsidio de Santa Fe de Bogotá, el Hospital Infantil Club Noel de Cali y el Hospital Pediátrico de Barranquilla (Colombia), entre diciembre de 2003 y diciembre de 2004

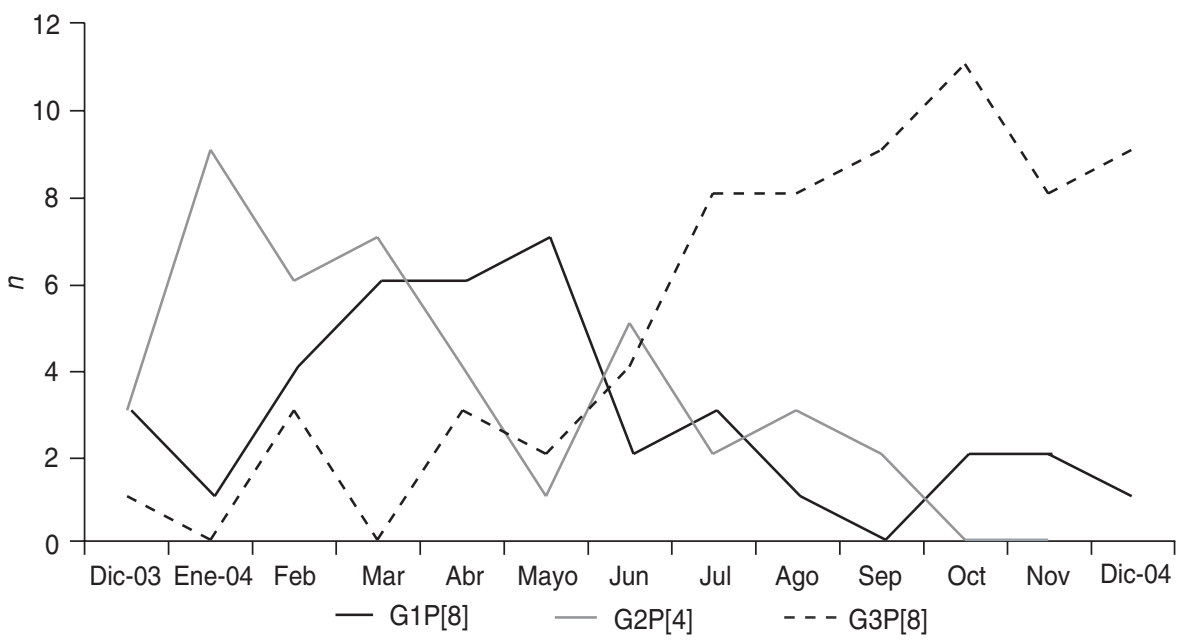

lo tanto, es necesario que las estrategias de prevención de la deshidratación por diarrea logren un alto impacto en los primeros 6 meses de vida de los niños, con el fin de reducir la mortalidad por diarrea. En esta situación, la vacunación contra el rotavirus puede contribuir a alcanzar este objetivo y, de esta forma, a lograr uno de los Objetivos de Desarrollo del Mile- embargo, en Barranquilla la hospitalización de menores de 6 meses fue significativamente mayor y solo en esta ciudad se observó mortalidad por diarrea. A diferencia de Bogotá y Cali, donde la mayoría de los niños pertenecían al régimen contributivo o se atendieron como particulares, en Barranquilla casi la totalidad de la población pertenecía al régimen subsidiado o no tenía afiliación a la seguridad social de salud. Esto indica que si bien el rotavirus afecta a los niños independientemente del estado socioeconómico de la familia, la infección en la población más pobre y vulnerable ocurre en edades más tempranas, lo que favorece la gravedad de la enfermedad y la muerte por diarrea.

A pesar de los enormes beneficios que aportaría la vacunación contra el rotavirus, para evaluar la relación de costo-efectividad de esta medida se requieren estudios económicos que permitan al gobierno tomar decisiones basadas en datos científicos e invertir los recursos disponibles para la promoción, la prevención y la atención de los menores de 5 años, según las necesidades de la población. Asimismo, es necesario tener en cuenta la eficacia de las vacunas disponibles contra los genotipos de rotavirus que circulan en Colombia.

Es posible que la frecuencia de infección por rotavirus en los niños que fallecieron fuera mayor a la observada e incluso a la encontrada entre los niños hospitalizados. Más del 50\% de los niños murió en las primeras 48 horas después del ingreso, sin que se pudiera tomar una muestra de materia fecal para confirmar o descartar el diagnóstico. La probabilidad de infección en estos niños es mayor, teniendo en cuenta que un porcentaje importante presentó choque hipovolémico, desequilibrio hidroelectrolítico o acidosis metabólica, complicaciones que se relacionan con el gradiente biológico más grave de la enfermedad.

Por esta razón, en estudios futuros es recomendable contar con métodos diagnósticos de infección por rotavirus en muestras diferentes de materia fecal o métodos de toma de muestra diferentes de la deposición espontá- 
nea, con el fin de evaluar la relación entre la infección viral y la mortalidad por diarrea en los niños que llegan gravemente enfermos a los hospitales.

Los genotipos encontrados en el estudio son similares a los hallados en otros países del mundo $\mathrm{y}$, en especial, de Latinoamérica (7-8, 10-18). Es necesario mantener la vigilancia del rotavirus para comprender mejor las variaciones estacionales en los genotipos y serotipos que circulan en el país, especialmente si la vacuna se incluye en el programa de inmunizaciones o en la práctica médica privada.

Uno de los resultados más interesantes del presente estudio fue la identificación de un patrón estacional en los genotipos de rotavirus, que no varió a pesar de la distancia geográfica entre las ciudades o las diferencias de temperatura, humedad y precipitación. En la literatura revisada no se encontró una descripción anterior de esta característica, aunque se observó una amplia variación de los tipos según el país y los años estudiados. Es posible que este patrón sea el producto de la relación entre la gran sensibilidad de los niños a la infección, la circulación de diferentes genotipos en distintas épocas del año y la protección colectiva de la población por inmunidad natural. Por lo tanto, la continuación de la vigilancia del rotavirus contribuirá a entender un poco más el comportamiento de este virus en los países tropicales.

Otro hallazgo interesante fue la gran similitud entre la distribución de rotavirus, norovirus, adenovirus y astrovirus en Barranquilla y la descrita por Kapikian et al. en los países en vías de desarrollo en 1996, es decir, casi una década antes (52). Lamentablemente, no fue posible comparar la distribución de las infecciones bacterianas y parasitarias porque no se realizaron las pruebas diagnósticas correspondientes.

Como se ha dicho anteriormente, en Barranquilla se encontró una proporción mayor de menores de 6 meses hospitalizados por diarrea. Por esta razón, se anidó un estudio de casos y testigos en el sistema de vigilancia intrahospitalaria. Se encontró una correlación entre la hospitalización de me- nores de 6 meses y, además de la edad, la duración de la lactancia materna inferior a 4 meses, la desnutrición (percentil de peso para talla inferior a 3 DE), los conocimientos de las madres sobre la prevención de la diarrea y la deshidratación, y la falta de afiliación a la seguridad social de salud, entre otros factores de riesgo. Estos resultados no se presentan en este artículo. Es posible que la relación compleja entre estos factores, además de la infección por rotavirus, favoreciera la mortalidad por diarrea. Se debe insistir en la importancia de ampliar las áreas de intervención y de evaluar y seguir el programa AIEPI, puesto que esta estrategia favorece el desarrollo adecuado de los niños y contribuye a disminuir la morbilidad por diarrea $y$ otras enfermedades trazadoras en menores de 5 años.

Por último, según la información recogida en las instituciones participantes, las hospitalizaciones por diarrea de menores de 5 años siguieron un patrón similar entre 2001 y 2004 en Cali, en 2001-2002 y 2003-2004 en Bogotá y en 2000 y 2004 en Barranquilla (datos de los registros de pacientes y de los departamentos de estadística de la Clínica Infantil Colsubsidio de Bogotá, el Hospital Pediátrico de Barranquilla y el Hospital Infantil Club Noel de Cali); estos datos no se presentan en este artículo. A diferencia de lo ocurrido en 2004, no se observó en Barranquilla en los años anteriores un incremento abrupto e importante de las hospitalizaciones por enfermedad diarreica aguda que pudiera deberse a un brote. Por lo tanto, se puede esperar que la tendencia, la estacionalidad y el peso de la enfermedad por rotavirus se mantengan con variaciones discretas en los próximos años.

En conclusión, la infección por rotavirus es una causa importante de morbilidad y mortalidad por diarrea, especialmente en los primeros años de vida, cuando el riesgo de complicación grave es mayor. Por lo tanto, es necesario que las estrategias de prevención tengan un alto impacto en los primeros 6 meses de vida de los niños. Se debe continuar la vigilancia del rotavirus para evaluar el impacto de la vacu- nación, tanto en la salud de los niños como en los servicios de salud, en caso de que esta vacuna se incluya en el esquema nacional de inmunizaciones o se utilice en la práctica médica privada. Los estudios de costo-efectividad de la vacuna contra el rotavirus servirán para que el gobierno tome decisiones basadas en datos científicos e invierta los recursos disponibles para la atención de los menores de 5 años, según las necesidades de la población. Tras la identificación de un patrón estacional en los genotipos de rotavirus, la continuación de la vigilancia intrahospitalaria ayudará a comprender mejor el comportamiento de este virus.

Agradecimientos. A Guillermo Orjuela, asesor de la Dirección General del Instituto Nacional de Salud (INS), por su interés, sus sugerencias y su colaboración. A Carlos Jorge Rodríguez, Director General de Planeación y Análisis de Política del Ministerio de la Protección Social, por facilitar el acceso a la base de datos RIPS de la diarrea en Colombia. A Elmer Escobar, ex Representante de la OPS/OMS, por las sugerencias y comentarios para mejorar el presente texto. A Jon Gentsch, de los Centros para el Control y la Prevención de Enfermedades (CDC) de Atlanta, Georgia, Estados Unidos, por donar reactivos para realizar parte de la genotipificación y compartir el protocolo técnico de este procedimiento. A Desirée Pastor, consultora del PAI OPS/OMS de Colombia, por el apoyo brindado. A los directivos, los miembros de los comités de ética e investigaciones y el personal médico y administrativo del Hospital Pediátrico de Barranquilla, del Hospital Infantil Club Noel y de la Clínica Infantil Colsubsidio, por su apoyo y por facilitar el acceso a la información estadística institucional. A los encargados de la vigilancia y del laboratorio de Salud Pública de la Secretaria de Salud de Cali, por sus aportes para la elaboración del protocolo de articulación de la vigilancia de la parálisis flácida y la infección por rotavirus, y por su apoyo para realizar la prueba piloto de este protocolo. 


\section{REFERENCIAS}

1. Bern C, Martínez J, de Zoysa I, Glass R. The magnitude of global problem of diarrhoeal disease: a ten year update. Bull World Health Organ. 1992;70(6):705-14.

2. World Health Organization. The world health report 2003. Chapter 1. Global health: today's challenges. Ginebra. WHO; 2003.

3. Parashar D, Hummelman EG, Bresse JS, Miller M, Glass R. Global illness and deaths caused by rotavirus disease in children. Emerging Infect Dis. 2003;9(5):565-72.

4. Ahmad O, López A., Inoue M. Reevaluación de la disminución de la mortalidad infantil. Bull World Health Organ; Recopilación de artículos N. ${ }^{\circ} 4,2001$

5. Kosek M, Bern C, Guerrant R. The global burden of diarrhoeal disease, as estimated from studies published between 1992 and 2000 . Bull World Health Organ. 2003;81(3):197-204.

6. Cunliffe NA, Kilgore PE, Bresee JS, Steele AD, Luo N, Hart CA, et al. Epidemiology of rotavirus diarrhoea in Africa: a review to assess the need for rotavirus immunization. Bull World Health Organ. 1998;76(5):525-37.

7. Dormitzer P. Rotaviruses. Capítulo 146. En: Mandell GL, Bennett JE, Dolin R, eds. Mandell, Douglas and Bennett's principles and practice of infectious diseases. $6 .^{a}$ ed. Philadelphia: Elsevier Churchill Livingstone; 2005. Pp. 1902-13.

8. World Health Organization. Generic protocols for (i) hospital-based surveillance to estimate the burden of Rotavirus gastroenteritis in children and (ii) a community-based survey on utilization of health care services for gastroenteritis in children. Field test version. Geneva: WHO; 2002.

9. Organización Panamericana de la Salud, Organización Mundial de la Salud. Reunión regional sobre la implementación de la vigilancia epidemiológica de rotavirus. Lima: OPS, OMS; 2003. (PAHO/FCH/IM/2003-00005).

10. Glass R, Parashar U, Bresse J, Gentsch J, Turcios R, Jiang B. Rotavirus Vaccines. En: Ciro de Quadros, ed. Vaccines. Preventing disease protecting health. Washington, D.C.: Pan American Health Organization, 2004. Pp. 111-9.

11. Coluchi N, Munfor V, Manzur J, Vázquez C, Escobar M, Weber E, et al. Detection, subgroup specificity, and genotype diversity of rotavirus strains in children with acute diarrhea in Paraguay. J Clin Microbiol. 2002: 1709-14.

12. Santos N, Volotao E, Soares C, Albuquerque $\mathrm{MC}$, da Silva F, et al. Rotavirus strains bearing genotype G9 or P[9] recovered from brazilian children with diarrhea from 1997 to 1999. J Clin Microbiol. 2001:1157-60.

13. Rosa e Silva ML, Caravalho I, Gouvea V. 1998-1999 rotavirus seasons in Juiz de Fora, Mina Gerais, Brazil: detection of an unusual G3P[4] epidemic strain. J Clin Microbiol. 2002:2837-42.

14. Araujo IT, Ferreira MSR, Fíalo AM, Assis RM, Cruz CM, et al. Rotavirus genotype P[4]G9, P[6]G9 and P[8]G9 in hospitalized children with acute gastroenteritis in Rio de Janeiro, Brazil. J Clin Microbiol. 2001:1999-2001.
15. Arguelles $\mathrm{MH}$, Villegas GA, Castello A, Abrami A, Ghiringhelli PD, et al. VP7 and VP4 genotyping of human group A rotavirus in Buenos Aires, Argentina. J Clin Microbiol. 2000:252-9.

16. Bok K, Palacios G, Sijvager K. Matson D, Gómez J. Emergence of G9P[6] human rotavirus in Argentina: Phylogenetic relationship among G9 strains. J Clin Microbiol 2001:4020-5.

17. Santos N, Soares C, Volotao E, Albuquerque MC, Hoshino Y. Surveillance of rotavirus strains in Rio de Janeiro, Brazil, from 19971999. J Clin Microbiol. 2003;41(7):3399-402.

18. Urbina D, Rodríguez JG, Arzuza O, Parra E, Young $\mathrm{G}$, et al. $\mathrm{G}$ and $\mathrm{P}$ genotypes of rotavirus circulating among children with diarrhea in the Colombian northern coast. International Microbiol. 2004;7:113-20.

19. Colombia, Departamento Administrativo Nacional de Estadística. Mortalidad por grupos de edad y departamentos. Archivo de defunciones: Departamento Administrativo Nacional de Estadística; 1990-2001.

20. Guerrero CA, Moreno LP, Peñaranda J Acosta O. Caracterización electroferotípica de rotavirus aislados en infantes con gastroenteritis en la ciudad de Bogotá. Revista de la Facultad de Medicina, Universidad Nacional de Colombia. 1994;42(4):203-8.

21. Remolina A, García L, Arellana R, Llanos R, Galofre P, et al. La enfermedad diarreica aguda (E.D.A.). Estudios epidemiológicos en el departamento del Atlántico, Colombia. Salud Uninorte. Barranquilla (Col.). 1985;2(2): 71-9.

22. Arango a, Aguirre $\mathrm{C}$, Aristizabal L, Hassen $\mathrm{H}$. Frecuencia de rotavirus en niños menores de cinco años con diarrea aguda. Primer informe. Estudio en un grupo de niños de la ciudad de Medellín (Colombia). 1985; Salud Uninorte. Barranquilla (Col.). 1985;2(3):129-35.

23. Trujillo H, Jaramillo C, Restrepo M, Mejía GI, Zapata CT, et al. Rotavirus y otros enteropatógenos en la etiología de la diarrea aguda en Medellín, Colombia, 1982. Bol Oficina Sanit Panam. 1985;98(3):251-61.

24. Bermeo L. Mogollón D, Ariza F, Barrera J, Jerabek Lois, et al. Molecular characterization of rotavirus strains obtained from human diarrheic samples and their epidemiological implications. Universitas Scientiarum. Rev. de la Facultad de Ciencias. Pontifica Universidad Javeriana. 1997;4(1):71-81.

25. Gutiérrez MF, Serrano $P$, Vanegas CA, Macías A, Riaño M. Efecto de las variaciones climáticas en gastroenteritis causadas por rotavirus y adenovirus en niños menores de cuatro años en Santafé de Bogotá entre junio de 1996 y junio de 1998. Medicas UIS. Revista de los Estudiantes de Medicina de la Universidad Industrial de Santander. 2000;14:24-9.

26. Leal FJ, Franco G, Sandoval C, Gómez E, Buitrago B, Rodríguez G. Agentes etiológicos de diarrea aguda en Bogotá. Pediatrics. 1985; 21(2):8-32.

27. Correa A, Solarte $\mathrm{Y}$, Barrera J, Mogollón D, Gutiérrez MF. Caracterización molecular de rotavirus en la ciudad de Santafé de Bogotá,
Colombia. Determinación de electroferotipos y tipificación de una cepa por RT-PCR. Rev. Latinoamer. de Microbiol. 1999; 41:167-73.

28. Mora J, Juliao O, Suescún J, Guzmán M. Estudio longitudinal sobre la epidemiología de la enfermedad diarreica aguda en los niños de una comunidad urbana pobre de Bogotá, Colombia. Escuela Colombiana de Medicina. 1988; 1(2):93-120.

29. Máttar $S$, Pulido N, Mulett R, Londono D, Medina G, Martínez M, et al. Aetiology of acute infectious diarrhoea in a private hospital in Colombia. Med Sci Res. 1999;27: 29-32.

30. Cáceres D, Estrada E, de Antonio R, Peláez D. La enfermedad diarreica aguda: un reto para la salud pública. Rev Panam Salud Publica. 2005;17(1):6-13.

31. Bennett AE, Ritchie K. Questionnaires in medicine. A guide to their design and use. London: Oxford University Press; 1975.

32. Centers for Disease Control and Prevention, World Health Organization. Epi-Info 6.04d. Atlanta: CDC, WHO; 2001.

33. Stata Corporation. Stata 5.0, statistics/data analysis. College Station (Texas): Stata Corporation; 1984-1997.

34. Rothman K, Greenland S. Modern epidemiology. Second edition. Philadelphia: LippincottRaven Publishers; 1998.

35. MacMahon B, Tricopoulos D. Epidemiología. 2.a ed. Boston: Lippincott Williams \& Wilkins; 2001.

36. McCullagh P, Nelder JA. Generalized Linear Models. Cambridge, UK: University Press; 1983.

37. Aguirre J. Introducción al Tratamiento de las Series Temporales. Aplicación a las ciencias de la salud. Madrid: Díaz de Santos; 1994

38. Huttly SRA, Morris SS, Pisani V. Prevention of diarrhoea in young children in developing countries. Bull World Health Organ. 1997; 75(2):163-74.

39. Victora GC, Smith PG, Vaughan JP, Nobre LC, Lombardi C, Texeira AM, et al. Infant feeding and deaths due to diarrhea: a case-control study. Am J Epidemiol. 1989;129:1032-41.

40. Victora GC, Smith PG, Vaughan JP. Evidence for protection by breast-feeding against infant deaths from infectious diseases in Brazil. Lancet. 1987;21:319-22.

41. Ahmed F, Clemens JD, Rao MR, Sack DA Khan MR, Haque E. Community based evaluation of the effect of breast-feeding on the risk of microbiologycally confirmed or clinically presumptive shigellosis in Bangladeshi children. Pediatrics.1992;90:406-11.

42. Peterson AE, Roberts L, Toole MJ, Peterson DE. The effect of soap distribution on diarrhoea: Nyamithuthu Refugee Camp. Int J Epidemiol. 1998;27:520-24.

43. Chen L, Hill A, Murray CJL. A critical analysis of design, results and implications of the mortality and use of health services surveys. Int J Epidemiol. 1993;22(Supl1):73-80.

44. Taylor WR, Chahnazarian A, Weinman J, Wernette M, Roy J, Pebley AR, et al. Mortality and use of health services surveys in rural Zaire. Int J Epidemiol. 1993;22(Supl1):15-9. 
45. Chahnazarian A, Ewbank D, Makani B, Ekouevi K. Impact of selective primary care on childhood mortality in rural health zone of Zaire. Int J Epidemiol. 1993;22(Supl1): 32-41.

46. Fuchs SC, Victora CG, Wannmacher L, Goncalves C, Barbosa A, Menta L et al. Reliability of environmental, biological and health characteristics of infants from a developing country. Int J Epidemiol. 1996;25:1005-8.

47. Snow RW, Chellenberg JR, Forster D, Mung'ala VO, Marsh K. Factors influencing admission to hospital during terminal childhood illness in Kenya. Int J Epidemiol. 1994; 23:1013-9.
48. Lombrail P, Vitoux-Brot C, Bourrillon A, Brodin M, De Pouvourville G. Another look at emergency room overcrowding: accessibility of the health service and quality of care. Int J Qual Health Care. 1997;9:225-35.

49. Goodman DC, Fisher E, Stukel TA, Chang C. The distance to community medical care and the likelihood of hospitalization: is closer always better? Am J Public Health. 1997;87(7): 1144-50.

50. Urrestarazu MI, Liprandi F, Pérez E, González R, Pérez-Schael I. Características etiológicas, clínicas y sociodemográficas de la diarrea aguda en Venezuela. Rev Panam. Salud Publica. 1999;6(3):149-56.
51. Callejas D, Estévez J, Porto-Espinoza L, Monsalve F, Costa-León L, Blitz L, et al. Influencia de los factores climatológicos en la epidemiología de la infección por rotavirus en los niños menores de 5 años de la ciudad de Maracaibo, Venezuela. Invest Clin. 1999; 40(2):81-94.

52. Kapikian AZ, Chanock RM. Rotaviruses. En: Fields Virology. 3rd ed. Philadelphia, PA: Lippincott-Raven; 1996:1659.

Manuscrito recibido el 9 de septiembre de 2005. Aceptado para publicación, tras revisión, el 1 de junio de 2006

ABSTRACT Objectives. To establish an in-hospital surveillance system for diarrhea in children under five, to estimate the burden of rotavirus-related disease, and to identify the most common rotavirus genotypes.

Burden of rotavirus-related disease among children under five, Colombia, 2004

Methods. Included in the study were children who were hospitalized for serious complications of diarrhea in three medical care facilities in Bogotá, Barranquilla, and Cali, Colombia. A solid-phase enzyme-linked immunosorbent assay (ELISA) was used to detect rotavirus, and reverse-transcriptase polymerase chain reaction (RTPCR) was the genotyping method employed. The frequencies, central tendency, and dispersion of the variables were determined. Stratified analysis and bivariate analysis were performed by applying a chi squared test or Fisher's exact test, or a chi squared test for trends, depending on the type of data analyzed. Relative risks were established. For analyzing trends we performed linear regression and calculated correlation coefficients and $P$ values.

Results. Between December 2003 and November 2004, 893 children were hospitalized in the three participating centers included in the study. Of these children, $68 \%$ were between 6 and 23 months of age; $2.7 \%$ of hospitalized patients showed clinical signs of hypovolemic shock, and $1.2 \%$ died. Only $57 \%$ of the mothers had given their children an oral rehydration solution before hospitalization. Rotavirus infection was the cause of $50 \%$ of hospitalizations (correlation coefficient $[r]>0.8$ ) and was linked to an inability to hold down orally-ingested fluids (relative risk $[R R]=1.45 ; 95 \%$ confidence interval [95\% CI]: 1.24 to $1.69 ; P<0.0000$ ) and to intractable vomiting (RR = 1.47; 95\% CI: 1.16 to $1.86 ; P<0.01)$. Rotavirus infection led to one death per 2000 children; 16 hospitalizations per 1000 children, and 631 medical visits per 1000 children. A seasonal trend was noted for G1P[8], G2P[4], and G3P[8] rotavirus genotypes, and this did not vary as a result of geographic distance or differences in temperature, humidity, and rainfall among cities.

Conclusions. Rotavirus infection is an important cause of morbidity and mortality from diarrhea, particularly during the first years of life, when children are more susceptible to serious complications. It is important for prevention strategies to have a high impact before 6 months of age, and vaccination against rotavirus can be a good complementary intervention strategy. No description was found in the international scientific literature of the seasonal variations in rotavirus genotypes. It is important to carry out cost-effectiveness studies in order to promote the investment of resources in accordance with population needs, and to continue surveillance activities so as to better understand how the virus behaves.

Key words Epidemiologic surveillance, rotavirus, prevention, vaccination, Colombia. 